\title{
Exhaled biomarkers in childhood asthma: old and new approaches
}

\author{
Valentina Ferraro ${ }^{* \dagger}$, Silvia Carraro ${ }^{\dagger}$, Sara Bozzetto, Stefania Zanconato and Eugenio Baraldi
}

\begin{abstract}
Background: Asthma is a chronic condition usually characterized by underlying inflammation. The study of asthmatic inflammation is of the utmost importance for both diagnostic and monitoring purposes. The gold standard for investigating airway inflammation is bronchoscopy, with bronchoalveolar lavage and bronchial biopsy, but the invasiveness of such procedures limits their use in children. For this reason, in the last decades there has been a growing interest for the development of noninvasive methods.

Main body: In the present review, we describe the most important non-invasive methods for the study of airway inflammation in children, focusing on the measure of the fractional exhaled nitric oxide (feNO), on the measure of the exhaled breath temperature (EBT) and on the analysis of both exhaled breath condensate (EBC) and exhaled air (Volatile Organic Compounds, VOCs), using targeted and untargeted approaches. We summarize what is currently known on the topic of exhaled biomarkers in childhood asthma, with a special emphasis on emerging approaches, underlining the role of exhaled biomarkers in the diagnosis, management and treatment of asthma, and their potential for the development of personalized treatments.

Conclusion: Among non-invasive methods to study asthma, exhaled breath analysis remains one of the most interesting approaches, feNO and "-omic" sciences seem promising for the purpose of characterizing biomarkers of this disease.
\end{abstract}

\section{Background}

Asthma is a common, potentially severe chronic disease that in the majority of cases can be treated effectively to control the symptoms and minimize the risk of flare-ups (exacerbations). It usually involves chronic airway inflammation [1]. Asthma affects about 300 million individuals worldwide, and $5-20 \%$ of school-age children in Europe [1]. Its prevalence has been increasing in the last two decades, and childhood asthma has become a serious public health problem because of its morbidity and related healthcare costs. The main pathophysiological features of asthma are bronchial obstruction (due to bronchial muscle constriction, mucosal edema and excessive airway secretions) and airway inflammation, but its underlying pathogenic mechanisms have yet to be fully characterized [2-5]. Indeed, it is nowadays well known that the term asthma is applied to an

\footnotetext{
* Correspondence: ferrarovalentina@hotmail.com

† alentina Ferraro and Silvia Carraro contributed equally to this work.

Women's and Children's Health Department, University of Padova, Padova, Italy
}

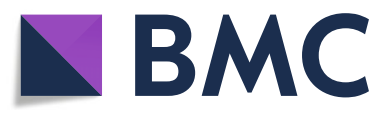

(c) The Author(s). 2018 Open Access This article is distributed under the terms of the Creative Commons Attribution 4.0 International License (http://creativecommons.org/licenses/by/4.0/), which permits unrestricted use, distribution, and

reproduction in any medium, provided you give appropriate credit to the original author(s) and the source, provide a link to the Creative Commons license, and indicate if changes were made. The Creative Commons Public Domain Dedication waiver (http://creativecommons.org/publicdomain/zero/1.0/) applies to the data made available in this article, unless otherwise stated. ized by fixed or labile airflow limitation, by different patterns of inflammation, by different contribution from bacterial and viral infections, by varying degrees of cough reflex and of mucus hypersecretion [6].

A number of pathogenic factors have been identified for this complex syndrome (asthma), including genetic predisposition and several environmental factors. Also early-life events may have a close link to the development of respiratory diseases throughout the lifespan [25]. Viral infections, exposure to tobacco smoke, and nutritional factors are just some of the early environmental noxae that can have a role in the development of asthma and that may orient the search for new strategies for the early prevention of this condition [7-9].

The key to the disease's pathogenesis lies in the interaction between the host and the environment, which gives rise to different clinical phenotypes with different wheezing patterns (early, transient, persistent, late-onset), different types of airway inflammation (eosinophilic, neutrophilic, paucicellular), and a different 
response to treatment [10]. Although these phenotypes are usually clinically relevant, they do not necessarily offer any insight about the underlying disease processes. That is why the concept of asthma endotypes has recently been introduced, paving the way to the classification of asthma in subtypes depending on the underlying functional and pathophysiological mechanisms [11]. This approach seems promising for the purpose of improving our understanding of the disease's pathogenesis $[12,13]$. In this setting, it is fundamental to search for biomarkers capable of orienting the diagnosis, management and treatment of asthma, and possibly facilitating the development of personalized treatments [14]. This could lead to a new precision medicine type approach, which firstly identifies the pathological process through non-invasive measures of airway inflammation rather than traditional symptoms and lung-function [6].

The gold standard for investigating airway inflammation is bronchoscopy, with bronchoalveolar lavage (BAL) and bronchial biopsy, but the invasiveness of such procedures limits their use in children [15]. Airway inflammation might feasibly be studied by analyzing sputum too, since its cell content correlates strongly with that of BAL fluids. Sputum induction is also less invasive than bronchoscopy, but sputum analysis is technically complicated and suffers from a marked variability in routine clinical use $[15,16]$.

Given the drawbacks of the invasive tests available, much effort has gone into developing noninvasive methods to investigate the pathogenic mechanisms underlying asthma, based on exhaled breath analysis. Of course, the noninvasiveness of a test is particularly important when investigating childhood asthma (Fig. 1).

Here we discuss some of the methods that have been studied in recent years for their possible role in asthma characterization. The potential clinical applications and future directions for these methods are summarized in Table 1.

\section{Fractional concentration of exhaled nitric oxide (feNO)}

The first report on the presence of gaseous nitric oxide in exhaled human breath dates from 1993 [17]. Four years later, it was found in higher than normal concentrations in children with asthma [18], and higher still during asthma exacerbations, while it dropped rapidly following oral steroid therapy [19]. As a result, the early 2000s saw a considerable number of publications exploring the relationship between fractional concentrations of exhaled nitric oxide (feNO) and asthma. Nitric oxide in the respiratory system is produced mainly by two enzymes: constitutive nitric oxide synthase (NOS), which constantly generates low concentrations of $\mathrm{NO}$, and inducible NOS (iNOS), the expression of which is prompted by various inflammatory cytokines [20,21].

FeNO can be measured using chemiluminescence and electrochemical sensors. The online single breath (SBOL) method is noninvasive, rapid, repeatable, and reproducible, and it involves the subject inhaling through the mouth for 2-3 s, to total lung capacity (TLC), then slowly exhaling immediately in conditions of velum closure (achieved by using a positive pressure of 5-20 $\mathrm{cmH} 2 \mathrm{O}$ against the exhalation) $[17,22,23]$.

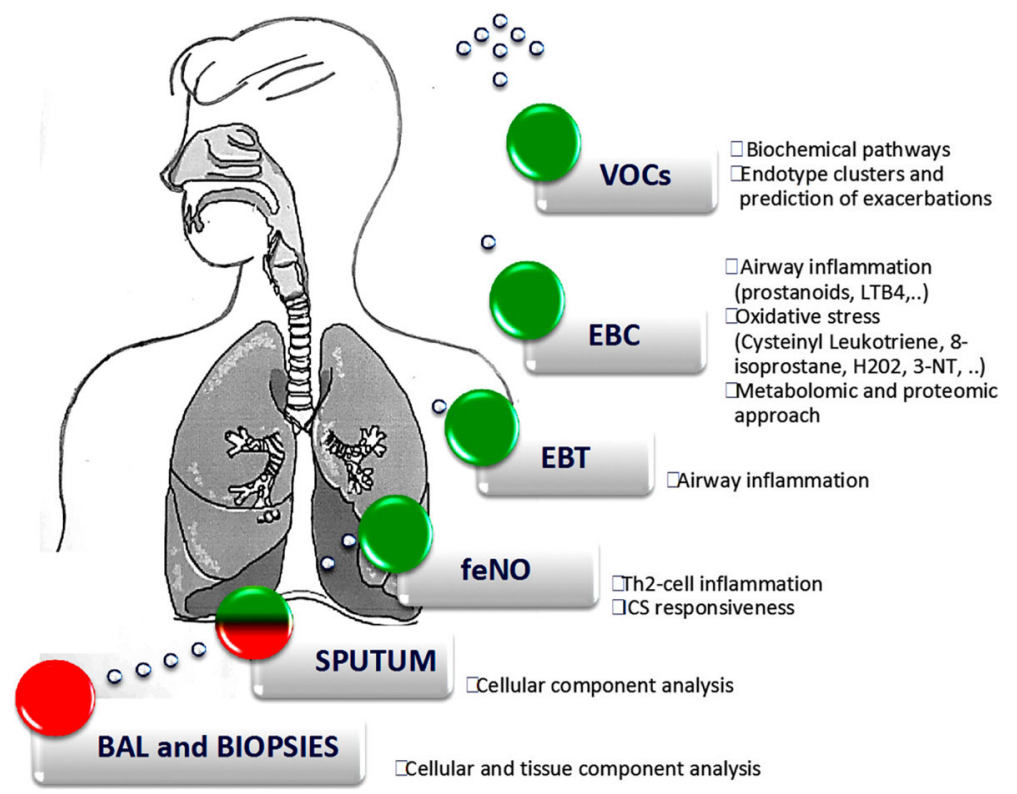

Fig. 1 Methods for investigating airway inflammation. Red = strongly invasive, red and green = mildly invasive, and green = noninvasive 
Table 1 Potential clinical application and future directions for main exhaled biomarkers

\begin{tabular}{|c|c|}
\hline Exhaled Biomarkers & $\begin{array}{l}\text { Potential Clinical Applications } \\
\text { and Future Directions }\end{array}$ \\
\hline feNO & $\begin{array}{l}\text { Identification of early-onset } \\
\text { asthma among preschool } \\
\text { children with recurrent wheezing } \\
\text { Stratification of asthmatic patients } \\
\text { according to eosinophilic } \\
\text { inflammation (treatable trait) }\end{array}$ \\
\hline Analytes measured in EBC & $\begin{array}{l}\text { Patient phenotyping and prediction } \\
\text { of therapy response based on } \\
\text { specific biomarkers profiles }\end{array}$ \\
\hline VOCs in exhaled air & $\begin{array}{l}\text { Early asthma diagnosis } \\
\text { Patient stratification and phenotyping }\end{array}$ \\
\hline
\end{tabular}

feNO fractional exhaled nitric oxide, ICS inhaled corticosteroids, EBC exhaled breath condensate, VOCs volatile organic compounds

The SBOL technique is well standardized and can be easily applied in children who are able to cooperate [24]. For measuring exhaled NO in young or uncooperative children, several techniques have been developed, but they have the limitation of the lack of standardization [24-26].

Several potential applications of feNO have been explored in pediatric asthma, especially as a diagnostic tool, to predict response to ICS, and to guide patient management. Many studies found a correlation between feNO and sputum eosinophilia, blood eosinophilia, serum eosinophil cationic protein, and IgE levels [17, 27]. FeNO is consequently considered a marker of a common asthma endotype characterized by Th2-mediated airway inflammation, eosinophilia, and responsiveness to inhaled steroids [17, 27]. Since increased levels of feNO have also been described in other atopic conditions, it has been suggested that low feNO levels predict a non-eosinophilic asthma phenotype better than high levels can predict an eosinophilic one [28, 29]. On the other hand, a recent systematic review supports a role of feNO in ruling in rather than in ruling out asthma [30]. In line with this assumption, it has been suggested that feNO could help us to identify early-onset asthma among preschool-age children with recurrent wheezing [31-33].

FeNO is also seen as a marker capable of predicting ICS responsiveness, since several studies found that its levels dropped significantly in response to steroid therapy [34-36]. Earlier studies on the potential role of feNO in orienting treatment decisions did not consistently find it useful to include feNO analysis in a symptom-based approach to ICS treatment, but more recent evidence suggests that it could help preventing asthma exacerbations requiring oral steroids [20]. Some authors also suggested that fluctuating feNO levels, and their cross-correlation with symptoms, can generate useful information on asthma severity and control [37]. So, even if there is no clear evidence to support the use of feNO in addition to standard symptom-based management for day-to-day asthma control [38, 39], it may be that a therapy based on feNO levels could significantly improve symptom control in some sub-phenotypes of asthma. Further studies are needed, however, based on standardized protocols and comparable study designs, before exhaled NO can be used to adjust ICS dosage and for asthma management [20].

The good standardization of the technique for FENO measurement and the studies demonstrating its potential clinical applications led to its adoption as a guide for asthma management in NICE guidelines [40]. On the other hand GINA guidelines [1] do not recommend its clinical use, yet. As recently suggested by Pavord et al. FENO could indeed have a role in the stratification of patients according to the treatable trait of eosinophilic inflammation and as a possible guide for a more personalized therapeutic approach [6].

\section{Exhaled breath temperature (EBT)}

Exhaled breath temperature (EBT) measurement has been suggested as a noninvasive method to detect airway inflammation [41] and airway remodeling [42, 43].

Several methods have been proposed for measuring EBT, such as the rate of EBT increase, the peak of expiratory temperature (PET) and the plateau value at the end of expiration (PLET) [41, 44-47]. In pediatric population these techniques are not easy to apply, so a new and simplified device for measuring EBT during tidal breathing has been proposed [48, 49].

Previous studies demonstrated that in asthma EBT is related to the degree of airway inflammation [47], it increases in uncontrolled asthma and decreases in response to anti-inflammatory treatment $[48,50]$, it is significantly higher in patients with severe asthma compared to those with mild to moderate asthma [51] and it reflects changes in airway inflammation in children with virus-induced asthma exacerbations [52]. In contrast, other studies found no relationship between EBT and measures of asthma control [53].

Further studies are needed to standardize the method of EBT measurement and to better understand the usefulness of this biomarker in asthma diagnosis and monitoring in children.

\section{Exhaled breath condensate (EBC)}

Exhaled breath condensate (EBC) can be used as a noninvasive method for studying airway inflammation. EBC is collected by cooling exhaled air by contact with a cold surface or condenser $[18,54,55]$. EBC is therefore a diluted fluid, the volume of which is almost entirely water, and consequently its analysis requires the application of highly sensitive methods for a reliable assessment of the 
solutes [34]. EBC collection only requires tidal breathing and it can be done safely and with no adverse effects even in preschool age. Methods for EBC collection have been developed also for very young children and infants [56].

The collected condensate contains unstable volatile (e.g. $\mathrm{H}_{2} \mathrm{O}_{2}$ ) and semi- and non-volatile molecules (proteins and cytokines) carried by respiratory droplets [54, 55]. Its composition is believed to mirror that of the airway lining fluid, thus enabling a noninvasive study of pulmonary biochemical and inflammatory processes [18, 54, 57]. Many biomolecules, markers of airway inflammation and oxidative stress, have been identified and measured in the EBC of children with asthma [57].

Although it has a great potential as a noninvasive method for measuring asthma biomarkers, the main limitation toward the clinical application of EBC remains the lack of a systematic, meticulous description of how it should be collected, preserved and analyzed. Horvath et al. [34] recently published "A European Respiratory Society technical standard", which provides technical norms and recommendations for the collection and analysis of EBC samples. Future studies should include a systematic description of the methods used so that we can arrive at a genuine data reproducibility [34].

EBC has been studied through both a target approach (measurement of single analytes) and an untarget approach (omic techniques).

\section{Measurement of single analytes}

Many studies investigating airway inflammation have focused on eicosanoids, a large group of heterogeneous arachidonic acid metabolites produced by free-radical or enzymatic oxygenation, including prostanoids, leukotrienes and epoxides [58]. Leukotriene (LT) B4 is a potent inflammatory mediator and a chemoattractant for neutrophils that has a role in the pathophysiology of asthma. Increased levels of LTB4 have been found in the EBC of asthmatic children. Montuschi et al. demonstrated that they were about twice as high in steroid-naïve patients with asthma as in healthy subjects $[59,60]$.

Cysteinyl leukotrienes (LTC4, LTD4 and LTE4) are powerful constrictors and proinflammatory mediators that have been found in higher concentrations in the EBC of patients with asthma, and particularly in cases of unstable or severe asthma [61-64]. Our research group demonstrated that Cys-LT levels dropped after a 5-day course of oral prednisone treatment for asthma exacerbations, thus showing that corticosteroids can affect the rise in LT production associated with acute asthma exacerbations [63]. Meanwhile, Bodini et al. found that exhaled Cys-LT levels and the percentage of eosinophils in induced sputum were lower after allergen avoidance [60].
As for oxidative stress, several potential biomarkers have been measured in EBC, such as 8-isoprostane, and hydrogen peroxide $(\mathrm{H} 2 \mathrm{O} 2)$. 8-isoprostane is a prostaglandin-like compound produced by arachidonic acid peroxidation. It is found in significantly higher levels in EBC from children with asthma, especially during exacerbations. A 5-day course of oral prednisone lowers the levels of 8-isoprostane, though they remain higher than in controls. This finding suggests that corticosteroids may not be fully effective in controlling oxidative stress in children with an asthma exacerbation [63]. Another marker of oxidative stress collected in EBC is hydrogen peroxide ( $\mathrm{H} 2 \mathrm{O} 2)$, which derives from the inflamed airways releasing superoxide anions. A meta-analysis on asthmatic adults showed that $\mathrm{H} 2 \mathrm{O} 2$ concentrations in EBC are higher than normal in asthmatic patients, and correlate with disease severity, disease control, and response to steroid treatment $[65,66]$. They also decline in asthma patients treated with corticosteroids [66]. Similar findings in childhood asthma were reported by Jöbsis et al.: $\mathrm{H} 2 \mathrm{O} 2$ levels in the EBC of their asthmatic patients were significantly higher than in healthy controls, and especially so in the steroid-naïve patients [67].

The products of the nitric oxide pathway (NOx), such as 3-nitrotyrosine, nitrite and nitrate, can also serve as markers of oxidative stress when measured in EBC. 3-nitrotyrosine (3-NT) derives from the nitration of the amino acid tyrosine and may serve as a biomarker of the generation of reactive nitrogen intermediates. EBC concentrations of 3-NT in asthmatic children are five times higher than in healthy controls, with no difference between steroid-naive and unstable steroid-treated asthmatic patients [68]. Two pediatric studies also found that asthmatic children had significantly higher mean nitrite/nitrate levels than their healthy counterparts, but there are conflicting results on the association between these molecules and asthma severity [69-71].

\section{Proteomics and metabolomics}

When it comes to studying complex chronic diseases like asthma, no single biomarker can describe a full picture of the underlying pathogenic processes, but each biomarker analyzed can shed light on the mechanisms involved. On the other hand, using the "-omic" sciences enables large datasets to be obtained from single samples, potentially leading to the identification of disease biomarkers, and to the characterization of novel functional or pathological mechanisms [72]. Proteomics and metabolomics are among the "-omic" approaches applied to the study of asthma.

Proteomics involves studying the full complement of proteins in a biological sample to quantify potential biomarkers associated with a given disease [72]. Bloemen et al. used proteome analysis to study disease-specific 
proteolytic peptide or protein patterns in EBC samples from 30 healthy children and 40 children with asthma. The authors found a specific pattern of differentially expressed peptides in the two groups, but it is still impossible to identify individual peptides because they occur in very limited quantities and we still lack the necessary analytical sensitivity [73].

Metabolomics is an unbiased approach that, being guided by no a priori hypothesis, enables the metabolite composition of a biological sample (or metabolome) to be studied using a spectroscopic technique (usually NMR spectroscopy and mass spectrometry). The metabolome provides a picture of the state of metabolic activity that is the result of both genetic influences and environmental stimuli [74]. That is why metabolomics is considered the "-omic" science that comes closest to phenotype expression, giving us the chance to look at both genotype-phenotype and genotype-envirotype relationships [75], as well as providing a tool for studying how an organism responds to exposure to risk factors [74]. The small molecules constitute the metabolome mark fingerprints, which can be associated with phenotypes and endotypes of a given clinical condition [74]. In the study of asthma, metabolomics has been applied to several biological matrixes, including exhaled air and exhaled breath condensate.

The metabolomic analysis of EBC samples enables us to distinguish between children with and without asthma [76]. Different EBC metabolomic profiles have also been associated with different asthma phenotypes, and a particular metabolomic profile has emerged in the characterization of severe asthma [77]. Applying the metabolomic approach to blood samples also reveals a metabolic profile associated with severe asthma, including metabolites related to oxidative stress [78].

Taken together, all these studies strongly support the potential for using the -omic approaches in asthma research, though we need to consider the current limits of this approach, due largely to the lack of a standardized EBC collection method. Nonetheless, before metabolomic findings can be useful in clinical practice, they need to be replicated in multicenter studies on childhood asthma (external validation), and biomarkers identified by the untargeted metabolomic approach need to be confirmed and quantified using targeted approaches.

\section{Volatile organic compounds (VOCs)}

VOCs originate from the lungs or upper airways and from blood circulation and they spread from the pulmonary capillary bed into the alveoli. They have been analyzed in exhaled breath using a metabolomic approach in the study of several chronic respiratory diseases, including asthma [71]. The fingerprint of VOCs in exhaled breath is called "breathome" and its study is called "breathomics" [79].
Different methods have been proposed for breath sampling. Among them the Breath Free Sampler is a highly standardized method enabling the collection of different breath volumes for a direct or offline analysis (details available at http://www.breathe-free.org). Breath Free Sampler is characterized by high repeatability and reproducibility, but it currently awaits validation in clinical trials [34].

Two different techniques have been used to study exhaled VOC profiles: (i) gas chromatography with mass spectrometry, a quantitative method that enables individual components to be identified; and (ii) the electronic Nose (e-Nose), a qualitative method that relies on a pattern-recognition technology to obtain a probabilistic discrimination between biomarker profiles [80, 81]. VOC collection is influenced by environmental, physiological and methodological factors, including conditions existing before, during and after their collection [34, 82].

Dallinga et al. found that analyzing VOCs in exhaled air using GC-MS could distinguish between children with and without asthma [83]. Other studies suggest that the analysis of exhaled VOC profiles is a promising non-invasive method for asthma diagnosis [79], monitoring [84-86], phenotyping and identification of treatable traits [87].

Pre-school children with acute respiratory wheeze have a different VOC profile compared to children with no wheezing, and such profile remains altered even after symptoms resolution in children with rhinovirus-induced wheeze [88]. Furthermore, in preschool-age children with recurrent wheezing, VOC profiles could discriminate between children with preclinical asthma and those with a transient form of wheezing, significantly improving on the prediction based on clinical data alone $[89,90]$.

\section{Conclusion}

In the last 20 years, a great deal of research on the topic of asthma (particularly in children) has focused o noninvasive exhaled biomarkers. FeNO measurements cannot be routinely recommended for all children with asthma, but it could have a role in the characterization of a specific treatable trait (Th2-mediated eosinophilic inflammation). Exhaled breath analysis remains one of the most interesting approaches for studying childhood asthma, and "-omic" approaches seem promising for the purpose of characterizing biomarkers associated with specific asthma endotypes.

\footnotetext{
Authors' contributions

VF made substantial contributions to acquisition, analysis and interpretation of data and drafted the manuscript. SC made substantial contributions to acquisition, analysis and interpretation of data and revised critically the manuscript for important intellectual content. SB helped to draft the manuscript. SZ revised critically the manuscript for important intellectual content. EB revised critically the manuscript for important intellectual content and gave final approval of the version to be published. All authors read and approved the final manuscript.
} 


\section{Ethics approval and consent to participate}

Not applicable.

\section{Consent for publication}

Not applicable.

\section{Competing interests}

The authors declare that they have no competing interests.

\section{Publisher's Note}

Springer Nature remains neutral with regard to jurisdictional claims in published maps and institutional affiliations.

\section{Received: 16 February 2018 Accepted: 30 July 2018}

\section{Published online: 07 August 2018}

\section{References}

1. (*NEW) 2018 GINA Report: Global Strategy for Asthma Management and Prevention [Internet]. Global Initiative for Asthma - GINA. Available from: https://ginasthma.org/2018-gina-report-global-strategy-for-asthmamanagement-and-prevention/. Cited 20 Jun 2018.

2. Carraro S, Scheltema N, Bont L, Baraldi E. Early-life origins of chronic respiratory diseases: understanding and promoting healthy ageing. Eur Respir J. 2014;44(6):1682-96.

3. Noutsios GT, Floros J. Childhood asthma: causes, risks, and protective factors; a role of innate immunity. Swiss Med Wkly. 2014;144:w14036.

4. van Nimwegen FA, Penders J, Stobberingh EE, Postma DS, Koppelman GH, Kerkhof $\mathrm{M}$, et al. Mode and place of delivery, gastrointestinal microbiota, and their influence on asthma and atopy. J Allergy Clin Immunol. 2011;128(5):948-955.e1-3.

5. Bisgaard H, Hermansen MN, Buchvald F, Loland L, Halkjaer LB, Bønnelykke K, et al. Childhood asthma after bacterial colonization of the airway in neonates. N Engl J Med. 2007;357(15):1487-95.

6. Pavord ID, Beasley R, Agusti A, Anderson GP, Bel E, Brusselle G, et al. After asthma: redefining airways diseases. Lancet. 2018;391(10118):350-400.

7. Lemanske RF, Jackson DJ, Gangnon RE, Evans MD, Li Z, Shult PA, et al. Rhinovirus illnesses during infancy predict subsequent childhood wheezing. J Allergy Clin Immunol. 2005;116(3):571-7.

8. Robison RG, Kumar R, Arguelles LM, Hong X, Wang G, Apollon S, et al. Maternal smoking during pregnancy, prematurity and recurrent wheezing in early childhood. Pediatr Pulmonol. 2012;47(7):666-73.

9. Duijts L, Reiss IK, Brusselle G, de Jongste JC. Early origins of chronic obstructive lung diseases across the life course. Eur J Epidemiol. 2014;29(12):871-85.

10. Iordanidou M, Loukides S, Paraskakis E. Asthma phenotypes in children and stratified pharmacological treatment regimens. Expert Rev Clin Pharmacol. 2017;10(3):293-303.

11. Lötvall J, Akdis CA, Bacharier LB, Bjermer L, Casale TB, Custovic A, et al. Asthma endotypes: a new approach to classification of disease entities within the asthma syndrome. J Allergy Clin Immunol. 2011;127(2):355-60.

12. Landgraf-Rauf $K$, Anselm B, Schaub B. The puzzle of immune phenotypes of childhood asthma. Mol Cell Pediatr. 2016;3(1):27.

13. Vock C, Hauber H-P, Wegmann M. The other T helper cells in asthma pathogenesis. J Allergy. 2010;2010:519298.

14. Moschino L, Zanconato S, Bozzetto S, Baraldi E, Carraro S. Childhood asthma biomarkers: present knowledge and future steps. Paediatr Respir Rev. 2015; 16(4):205-12.

15. Leung TF, Ko FWS, Wong GWK. Recent advances in asthma biomarker research. Ther Adv Respir Dis. 2013;7(5):297-308.

16. Vijverberg SJ, Hilvering B, Raaijmakers JA, Lammers J-WJ, Maitland-van der Zee A-H, Koenderman L. Clinical utility of asthma biomarkers: from bench to bedside. Biol Targets Ther. 2013;7:199-210.

17. Borland C, Cox Y, Higenbottam T. Measurement of exhaled nitric oxide in man. Thorax. 1993;48(11):1160-2.

18. Nelson BV, Sears S, Woods J, Ling CY, Hunt J, Clapper LM, et al. Expired nitric oxide as a marker for childhood asthma. J Pediatr. 1997;130(3):423-7.

19. Baraldi E, Azzolin NM, Zanconato S, Dario C, Zacchello F. Corticosteroids decrease exhaled nitric oxide in children with acute asthma. J Pediatr. 1997; 131(3):381-5.

20. Turner S. Exhaled nitric oxide and the management of childhood asthma-yet another promising biomarker "has been" or a misunderstood gem. Paediatr Respir Rev. 2015;16(2):88-96.
21. Kim HB, Eckel SP, Kim JH, Gilliland FD. Exhaled NO: Determinants and clinical application in children with allergic airway disease. Allergy, Asthma Immunol Res. 2016;8(1):12-21.

22. American Thoracic Society, European Respiratory Society. ATS/ERS recommendations for standardized procedures for the online and offline measurement of exhaled lower respiratory nitric oxide and nasal nitric oxide, 2005. Am J Respir Crit Care Med. 2005;171(8):912-30.

23. Dweik RA, Boggs PB, Erzurum SC, Irvin CG, Leigh MW, Lundberg JO, et al. An official ATS clinical practice guideline: interpretation of exhaled nitric oxide levels (FENO) for clinical applications. Am J Respir Crit Care Med. 2011;184(5):602-15.

24. Baraldi E, de Jongste JC, European Respiratory Society/American Thoracic Society (ERS/ATS) Task Force. Measurement of exhaled nitric oxide in children, 2001. Eur Respir J. 2002;20(1):223-37.

25. Baraldi E, Scollo M, Zaramella C, Zanconato S, Zacchello F. A simple flowdriven method for online measurement of exhaled NO starting at the age of 4 to 5 years. Am J Respir Crit Care Med. 2000;162(5):1828-32.

26. Franklin PJ, Turner SW, Mutch RC, Stick SM. Comparison of single-breath and tida breathing exhaled nitric oxide levels in infants. Eur Respir J. 2004;23(3):369-72.

27. Mahr TA, Malka J, Spahn JD. Inflammometry in pediatric asthma: a review of fractional exhaled nitric oxide in clinical practice. Allergy Asthma Proc. 2013;34(3): 210-9.

28. Taylor DR, Pijnenburg MW, Smith AD, De Jongste JC. Exhaled nitric oxide measurements: clinical application and interpretation. Thorax. 2006;61(9):817-27.

29. Moeller A, Carlsen K-H, Sly PD, Baraldi E, Piacentini G, Pavord I, et al. Monitoring asthma in childhood: lung function, bronchial responsiveness and inflammation. Eur Respir Rev. 2015;24(136):204-15.

30. Karrasch S, Linde K, Rücker G, Sommer H, Karsch-Völk M, Kleijnen J, et al. Accuracy of FENO for diagnosing asthma: a systematic review. Thorax. 2017;72(2):109-16.

31. Gabriele C, Nieuwhof EM, Van Der Wiel EC, Hofhuis W, Moll HA, Merkus PJFM, et al. Exhaled nitric oxide differentiates airway diseases in the first two years of life. Pediatr Res. 2006;60(4):461-5.

32. Oh M-A, Shim JY, Jung Y-H, Seo J-H, Young Kim H, Kwon J-W, et al. Fraction of exhaled nitric oxide and wheezing phenotypes in preschool children. Pediatr Pulmonol. 2013:48(6):563-70.

33. Caudri D, Wijga AH, Hoekstra MO, Kerkhof M, Koppelman GH, Brunekreef B, et al. Prediction of asthma in symptomatic preschool children using exhaled nitric oxide, Rint and specific IgE. Thorax. 2010;65(9):801-7.

34. Horváth I, Barnes PJ, Loukides S, Sterk PJ, Högman M, Olin A-C, et al. A European Respiratory Society technical standard: exhaled biomarkers in lung disease. Eur Respir J. 2017:49(4). https://doi.org/10.1183/13993003.00965-2016.

35. Baraldi E, Dario C, Ongaro R, Scollo M, Azzolin NM, Panza N, et al. Exhaled nitric oxide concentrations during treatment of wheezing exacerbation in infants and young children. Am J Respir Crit Care Med. 1999;159(4 Pt 1):1284-8.

36. Moeller A, Franklin P, Hall GL, Turner S, Straub D, Wildhaber JH, et al. Inhaled fluticasone dipropionate decreases levels of nitric oxide in recurrenty wheezy infants. Pediatr Pulmonol. 2004;38(3):250-5.

37. Stern G, de Jongste J, van der Valk R, Baraldi E, Carraro S, Thamrin C, et al. Fluctuation phenotyping based on daily fraction of exhaled nitric oxide values in asthmatic children. J Allergy Clin Immunol. 2011:128(2):293-300.

38. Petsky HL, Cates CJ, Lasserson TJ, Li AM, Turner C, Kynaston JA, et al. A systematic review and meta-analysis: tailoring asthma treatment on eosinophilic markers (exhaled nitric oxide or sputum eosinophils). Thorax. 2012;67(3):199-208.

39. Jartti T, Wendelin-Saarenhovi M, Heinonen I, Hartiala J, Vanto T. Childhood asthma management guided by repeated FeNO measurements: a metaanalysis. Paediatr Respir Rev. 2012;13(3):178-83.

40. Asthma: diagnosis, monitoring and chronic asthma management | Guidance and guidelines | NICE [Internet]. Available from: https://www.nice. org.uk/guidance/ng80. Cited 3 Jul 2018

41. Paredi $\mathrm{P}$, Kharitonov SA, Barnes PJ. Faster rise of exhaled breath temperature in asthma: a novel marker of airway inflammation? Am J Respir Crit Care Med. 2002;165(2):181-4.

42. Tufvesson $E$, Svensson $H$, Ankerst J, Bjermer L. Increase of club cell (Clara) protein (CC16) in plasma and urine after exercise challenge in asthmatics and healthy controls, and correlations to exhaled breath temperature and exhaled nitric oxide. Respir Med. 2013;107(11):1675-81

43. Piacentini GL, Peroni DG, Bodini A, Corradi M, Boner AL. Exhaled breath temperature as a marker of airway remodelling in asthma: a preliminary study. Allergy. 2008;63(4):484-5.

44. Piacentini GL, Bodini A, Zerman L, Costella S, Zanolla L, Peroni DG, et al. Relationship between exhaled air temperature and exhaled nitric oxide in childhood asthma. Eur Respir J. 2002;20(1):108-11. 
45. Paredi P, Kharitonov SA, Barnes PJ. Correlation of exhaled breath temperature with bronchial blood flow in asthma. Respir Res. 2005;6:15.

46. Piacentini GL, Bodini A, Peroni D, Ress M, Costella S, Boner AL. Exhaled air temperature and eosinophil airway inflammation in allergic asthmatic children. J Allergy Clin Immunol. 2004;114(1):202-4.

47. Piacentini GL, Peroni D, Crestani E, Zardini F, Bodini A, Costella S, et al. Exhaled air temperature in asthma: methods and relationship with markers of disease. Clin Exp Allergy. 2007;37(3):415-9.

48. Popov TA, Dunev S, Kralimarkova TZ, Kraeva S, DuBuske LM. Evaluation of a simple, potentially individual device for exhaled breath temperature measurement. Respir Med. 2007;101(10):2044-50.

49. Popov TA, Kralimarkova T, Tzachev C, Dimitrov V, Mun KK, Gill J. Exhaled breath temperature measurement made easy. Pediatr Allergy Immunol. 2009;20(2):200-1. author reply 202-203

50. Wojsyk-Banaszak I, Mikoś M, Szczepankiewicz A, Wielebska A, Sobkowiak P, Kamińska A, et al. Evaluation of exhaled breath temperature (EBT) as a marker and predictor of asthma exacerbation in children and adolescents. J Asthma. 2017;54(7):699-705.

51. Ntontsi P, Bakakos P, Papathanasiou E, Tsilogianni Z, Kostikas K, Hillas G, et al. Exhaled breath temperature in optimally treated asthmatics: severity and underlying mechanisms. J Breath Res. 2018:12(2):026013.

52. Xepapadaki P, Xatziioannou A, Chatzicharalambous M, Makrinioti $H$, Papadopoulos NG. Exhaled breath temperature increases during mild exacerbations in children with virus-induced asthma. Int Arch Allergy Immunol. 2010;153(1):70-4.

53. Hamill L, Ferris K, Kapande K, McConaghy L, Douglas I, McGovern V, et al. Exhaled breath temperature measurement and asthma control in children prescribed inhaled corticosteroids: a cross sectional study. Pediatr Pulmonol. 2016;51(1):13-21.

54. Carraro S, Baraldi E. Exhaled breath condensate in children: present knowledge and future prospects. J Breath Res. 2008;2(3):037003

55. Horváth I, Hunt J, Barnes PJ, Alving K, Antczak A, Baraldi E, et al. Exhaled breath condensate: methodological recommendations and unresolved questions. Eur Respir J. 2005;26(3):523-48.

56. Moeller A, Franklin P, Hall GL, Horak F, Wildhaber JH, Stick SM. Measuring exhaled breath condensates in infants. Pediatr Pulmonol. 2006:41(2):184-7.

57. Thomas PS, Lowe AJ, Samarasinghe P, Lodge CJ, Huang Y, Abramson MJ, et al. Exhaled breath condensate in pediatric asthma: promising new advance or pouring cold water on a lot of hot air? A systematic review. Pediatr Pulmonol. 2013;48(5):419-42.

58. Sanak M. Eicosanoid mediators in the airway inflammation of asthmatic patients: what is new? Allergy, Asthma Immunol Res. 2016;8(6):481-90.

59. Montuschi P. LC/MS/MS analysis of leukotriene B4 and other eicosanoids in exhaled breath condensate for assessing lung inflammation. J Chromatogr B Anal Technol Biomed Life Sci. 2009;877(13):1272-80.

60. Montuschi P, Barnes PJ. Exhaled leukotrienes and prostaglandins in asthma. J Allergy Clin Immunol. 2002;109(4):615-20.

61. Zanconato S, Carraro S, Corradi M, Alinovi R, Pasquale MF, Piacentini G, et al. Leukotrienes and 8-isoprostane in exhaled breath condensate of children with stable and unstable asthma. J Allergy Clin Immunol. 2004;113(2):257-63.

62. Wan G-H, Yan D-C, Tseng H-Y, Tung T-H, Lin S-J, Lin Y-W. Cysteinyl leukotriene levels correlate with 8-isoprostane levels in exhaled breath condensates of atopic and healthy children. Pediatr Res. 2013;74(5):584-91.

63. Baraldi E, Carraro S, Alinovi R, Pesci A, Ghiro L, Bodini A, et al. Cysteinyl leukotrienes and 8-isoprostane in exhaled breath condensate of children with asthma exacerbations. Thorax. 2003;58(6):505-9.

64. Samitas K, Chorianopoulos D, Vittorakis S, Zervas E, Economidou E, Papatheodorou G, et al. Exhaled cysteinyl-leukotrienes and 8-isoprostane in patients with asthma and their relation to clinical severity. Respir Med. 2009; 103(5):750-6.

65. Bodini A, Peroni D, Vicentini L, Loiacono A, Baraldi E, Ghiro L, et al. Exhaled breath condensate eicosanoids and sputum eosinophils in asthmatic children: a pilot study. Pediatr Allergy Immunol. 2004;15(1):26-31.

66. Teng Y, Sun P, Zhang J, Yu R, Bai J, Yao X, et al. Hydrogen peroxide in exhaled breath condensate in patients with asthma: a promising biomarker? Chest. 2011;140(1):108-16.

67. Jöbsis Q, Raatgeep HC, Hermans PW, de Jongste JC. Hydrogen peroxide in exhaled air is increased in stable asthmatic children. Eur Respir J. 1997;10(3):519-21.

68. Baraldi E, Giordano G, Pasquale MF, Carraro S, Mardegan A, Bonetto G, et al. 3-Nitrotyrosine, a marker of nitrosative stress, is increased in breath condensate of allergic asthmatic children. Allergy. 2006;61(1):90-6.
69. Ratnawati, Morton J, Henry RL, Thomas PS. Exhaled breath condensate nitrite/nitrate and $\mathrm{pH}$ in relation to pediatric asthma control and exhaled nitric oxide. Pediatr Pulmonol. 2006;41(10):929-36.

70. Formanek W, Inci D, Lauener RP, Wildhaber JH, Frey U, Hall GL. Elevated nitrite in breath condensates of children with respiratory disease. Eur Respir J. 2002;19(3):487-91.

71. van Mastrigt $\mathrm{E}$, de Jongste JC, Pijnenburg MW. The analysis of volatile organic compounds in exhaled breath and biomarkers in exhaled breath condensate in children - clinical tools or scientific toys? Clin Exp Allergy. 2015;45(7):1170-88.

72. Wheelock CE, Goss VM, Balgoma D, Nicholas B, Brandsma J, Skipp PJ, et al. Application of 'omics technologies to biomarker discovery in inflammatory lung diseases. Eur Respir J. 2013;42(3):802-25.

73. Bloemen K, Van Den Heuvel R, Govarts E, Hooyberghs J, Nelen V, Witters E, et al. A new approach to study exhaled proteins as potential biomarkers for asthma. Clin Exp Allergy. 2011;41(3):346-56.

74. Turi KN, Romick-Rosendale L, Ryckman KK, Hartert TV. A review of metabolomics approaches and their application in identifying causal pathways of childhood asthma. J Allergy Clin Immunol. 2018;141(4):1191-201.

75. Carraro S, Giordano G, Reniero F, Perilongo G, Baraldi E. Metabolomics: a new frontier for research in pediatrics. J Pediatr. 2009;154(5):638-44.

76. Carraro S, Rezzi S, Reniero F, Héberger K, Giordano G, Zanconato S, et al. Metabolomics applied to exhaled breath condensate in childhood asthma. Am J Respir Crit Care Med. 2007;175(10):986-90.

77. Carraro S, Giordano G, Reniero F, Carpi D, Stocchero M, Sterk PJ, et al. Asthma severity in childhood and metabolomic profiling of breath condensate. Allergy. 2013;68(1):110-7.

78. Fitzpatrick AM, Park Y, Brown LAS, Jones DP. Children with severe asthma have unique oxidative stress-associated metabolomic profiles. J Allergy Clin Immunol. 2014;133(1):258-261.e1-8.

79. Neerincx AH, Vijverberg SJH, Bos LDJ, Brinkman P, van der Schee MP, de Vries $\mathrm{R}$, et al. Breathomics from exhaled volatile organic compounds in pediatric asthma. Pediatr Pulmonol. 2017:52(12):1616-27.

80. van der Schee MP, Paff T, Brinkman P, van Aalderen WMC, Haarman EG, Sterk PJ. Breathomics in lung disease. Chest. 2015;147(1):224-31.

81. Fens N, van der Schee MP, Brinkman P, Sterk PJ. Exhaled breath analysis by electronic nose in airways disease. Established issues and key questions. Clin Exp Allergy. 2013;43(7):705-15.

82. van de Kant KDG, van der Sande LJTM, Jöbsis Q, van Schayck OCP, Dompeling E. Clinical use of exhaled volatile organic compounds in pulmonary diseases: a systematic review. Respir Res. 2012;13:117.

83. Dallinga JW, Robroeks CMHHT, van Berkel JJBN, Moonen EJC, Godschalk RWL, Jöbsis Q, et al. Volatile organic compounds in exhaled breath as a diagnostic tool for asthma in children. Clin Exp Allergy. 2010;40(1):68-76

84. Brinkman P, van de Pol MA, Gerritsen MG, Bos LD, Dekker T, Smids BS, et al. Exhaled breath profiles in the monitoring of loss of control and clinical recovery in asthma. Clin Exp Allergy. 2017;47(9):1159-69.

85. Robroeks CM, van Berkel JJ, Jöbsis Q, van Schooten F-J, Dallinga JW, Wouters EF, et al. Exhaled volatile organic compounds predict exacerbations of childhood asthma in a 1-year prospective study. Eur Respir J. 2013;42(1):98-106.

86. Van Vliet D, Smolinska A, Jöbsis Q, Rosias PPR, Muris JWM, Dallinga JW, et al. Association between exhaled inflammatory markers and asthma control in children. J Breath Res. 2016;10(1):016014.

87. Bos LD, Sterk PJ, Fowler SJ. Breathomics in the setting of asthma and chronic obstructive pulmonary disease. J Allergy Clin Immunol. 2016; 138(4):970-6.

88. van der Schee MP, Hashimoto S, Schuurman AC, van Driel JSR, Adriaens N, van Amelsfoort RM, et al. Altered exhaled biomarker profiles in children during and after rhinovirus-induced wheeze. Eur Respir J. 2015;45(2):440-8.

89. van Vliet D, Smolinska A, Jöbsis Q, Rosias P, Muris J, Dallinga J, et al. Can exhaled volatile organic compounds predict asthma exacerbations in children? J Breath Res. 2017;11(1):016016.

90. Klaassen EMM, van de Kant KDG, Jöbsis Q, van Schayck OCP, Smolinska A, Dallinga JW, et al. Exhaled biomarkers and gene expression at preschool age improve asthma prediction at 6 years of age. Am J Respir Crit Care Med. 2015:191(2):201-7. 